\title{
Cutinase and pectinase in cotton bioscouring: an innovative and fast bioscouring process
}

\author{
P. B. AGRAWAL ${ }^{\star}$, V. A. NIERSTRASZ, G. H. BOUWHUIS, \& \\ M. M. C. G. WARMOESKERKEN \\ Engineering of Fibrous Smart Materials, Department of Engineering Technology, University of Twente, Enschede, The \\ Netherlands
}

(Received 26 September 2007; accepted 1 April 2008)

\begin{abstract}
This manuscript describes the potential of a cutinase from the fungus Fusarium solani pisi for cotton wax degradation in order to design an efficient low temperature scouring process. The main characteristics, relevant to cotton wax removal with F. solani pisi cutinase are given. The additive effect of cutinase on pectinase was investigated and optimum incubation conditions were determined. Compatibility of cutinase with surfactants, essential for the rapid migration of enzymes into the fabric, is explored. A clear strategy is presented to achieve a rapid enzymatic cotton scouring process. Wax removal with cutinase reduces pectinase incubation time and increases the hydrolytic rate of pectinase. Cutinase appears to be effective in the degradation of cotton waxes at low-temperature, allowing the design and introduction of a competitive innovative enzymatic scouring process.
\end{abstract}

Keywords: Cutinase, pectinase, wax removal, scouring, cotton

\section{Introduction}

The technical feasibility of enzymatic scouring for cotton fabrics has been recognized by many researchers over the last decade (Li \& Hardin 1997; Hartzell-Lawson \& Hsieh 1998; Sawada et al. 1998; Etters et al. 1999; Buchert \& Pere 2000; Lin \& Hsieh 2001; Takagishi et al. 2001; Tzanko et al. 2001; Lenting et al. 2002; Degani et al. 2002; Lu 2005; Moghe \& Nabar 2006). However, enzymatic scouring has not yet been widely implemented by textile industries. The most important reason identified was the inability to remove cotton fibre waxes during enzymatic scouring (Agrawal et al. 2007; Lu 2005). The cuticle of the cotton fibre is cross-linked to the primary cell wall by esterified pectic substances, which hinder pectinase action on the pectin backbone. Cutin forms a three-dimensional network structure in which other amorphous waxy materials are embedded (Purdy et al. 1975; Kolattukudy 2001). Pre-rinsing in hot water $\left(>90^{\circ} \mathrm{C}\right)$ with a surfactant (Hartzell-Lawson \& Hsieh 1998) or extraction with boiled $n$-hexane helps to reduce wax impurities and, subsequently, results in better pectinase performance towards primary wall destabilization (Agrawal et al. 2007). The introduction of such a high temperature treatment hinders the development of a low-temperature scouring process. Therefore, the main challenge is to remove these cotton waxes at low-temperature effectively and efficiently via an environmentally benign route. Degani et al. (2002) were the first to report on the potential of cutinase from a bacterial source, Pseudomonas mandocino for wax degradation in cotton scouring. As proof of wax degradation, Degani et al. (2002) confirmed the release of $\mathrm{C}_{16}$ and $\mathrm{C}_{18}$ fatty acids using reverse phase-HPLC and GC-MS. To assess changes in hydrophilicity, they applied the 'drop test'. These results were encouraging, although their enzyme incubation times were between 10 and 20 hours, which is far too long to allow industrial implementation.

Correspondence: P. B. Agrawal, Engineering of Fibrous Smart Materials, Department of Engineering Technology, University of Twente, PO Box 217, 7500AE Enschede, The Netherlands. Tel: +31 53489 4860. Fax: +31 53489 3849. E-mail: p.b.agrawal@utwente.nl ^Present address: Department of Textiles, Ghent University, Technologiepark 907, 9052 Zwijnaarde (Ghent), Belgium. 
Cutinases are present in fungal and bacterial pathogens (Kolattukudy 2001) and are able to hydrolyse plant polyesters. Like lipases, cutinases are lipolytic enzymes with high activity towards their substrate in aggregated form, hence, they are suitable candidates for the cotton wax degradation (Purdy et al. 1975; Svendsen 2000). Cutinase has some advantages over lipases for cotton wax degradation. Lipases, in general, require interfacial activation at the lipid water interface, whereas cutinase does not. The interfacial activation is an extra energy required to expose the active site of lipase enzymes to the substrate. Unlike lipases, cutinase can hydrolyse waxes in the absence of $\mathrm{Ca}^{2+}$ ions (Egmond \& de Vlieg 2000; Svendsen 2000). The selection of a suitable pectinase for the destabilization of the primary wall of the cotton fibre is described earlier (Agrawal et al. 2007; Klug-Santner et al. 2006). It is possible to combine cutinase and pectinase for cotton scouring, because similar to pectinases, cutinase does not require $\mathrm{Ca}^{2+}$ ions for catalysis. Based on an extensive literature survey we selected a cutinase (EC 3.1.1.74) from fungal origin: cutinase from Fusarium solani pisi was identified as potential candidate for industrial cotton wax degradation.

A clear strategy has been developed and adopted, instead of a black box approach to achieve sufficient hydrophilicity at lower temperature without using hazardous chemicals. The proposed strategy for a new enzymatic scouring process is illustrated in Figure 1. A systematic study was conducted to characterize cutinase for the improvement of wetability of raw cotton fabrics, by hydrolysis of cutin in the cuticle. Cotton wax degradation at low temperature and within a short time was attempted, which is a prerequisite for the successful implementation of cutinase technology at an industrial scale. The effect of cutinase alone, as well as in combination with pectinase has been studied on cotton fabrics. Compatibility studies were conducted between different non-ionic surfactants and cutinase, which is essential for a better and faster scouring process. By specific degradation of the cuticle, an increase in pectinase action on the pectin backbone was expected. This would result in an improved destabilization of the primary wall and, consequently, an increased hydrophilicity of the cotton.

\section{Materials and methods}

Enzymes

Cutinase (EC 3.1.1.74) from Fusarium solani pisi was obtained from Unilever Research and Development Laboratory in the Netherlands. The original enzyme was in granulated form and was prepared for incubation according to the procedure describe by Vertommen et al. (2005). The prepared enzyme solution was stored at $4{ }^{\circ} \mathrm{C}$ and used within $24 \mathrm{~h}$ to prevent enzyme deactivation. The activity of cutinase was determined with a tributyrin assay in a $\mathrm{pH}-$ stat (Vertommen et al. 2005). 1 unit (U) is defined as $1 \mu \mathrm{mol}$ of liberated free fatty acid per minute. The $\mathrm{pH}$-stat measurements were also used to study the effect of different non-ionic surfactants on the cutinase activity, using tributyrin and cotton fabric as substrate. To study the release of fatty acids from the fabric, experiments were conducted at $\mathrm{pH} 9.5$ with $0.5 \mathrm{~g}$ of cotton fabric, using $2 \mathrm{mM}$ borax buffer, at $30^{\circ} \mathrm{C}$ for $15 \mathrm{~min} ; \mathrm{pH} 9.5$ is above the $\mathrm{pK}$ value of most $\mathrm{C}_{16}$ fatty acids present in cotton. At this $\mathrm{pH}$, the liberated fatty acids have a negative charge which is easy to monitor with the $\mathrm{pH}$-stat.

Pectinase (EC 4.2.2.2), Bioprep 3000L was obtained from Novozymes. It contains a mono-component pectate lyase, which is active in the alkaline $\mathrm{pH}$ range $(\mathrm{pH}$ 8-9) and was used as supplied. Bioprep $3000 \mathrm{~L}$ activity was determined by measuring the increase in reducing sugars released from the substrate poly-d-galacturonic acid (Miller 1959). 1U was defined as the amount of enzyme that released 1 mol reducing groups $\mathrm{s}^{-1}$.

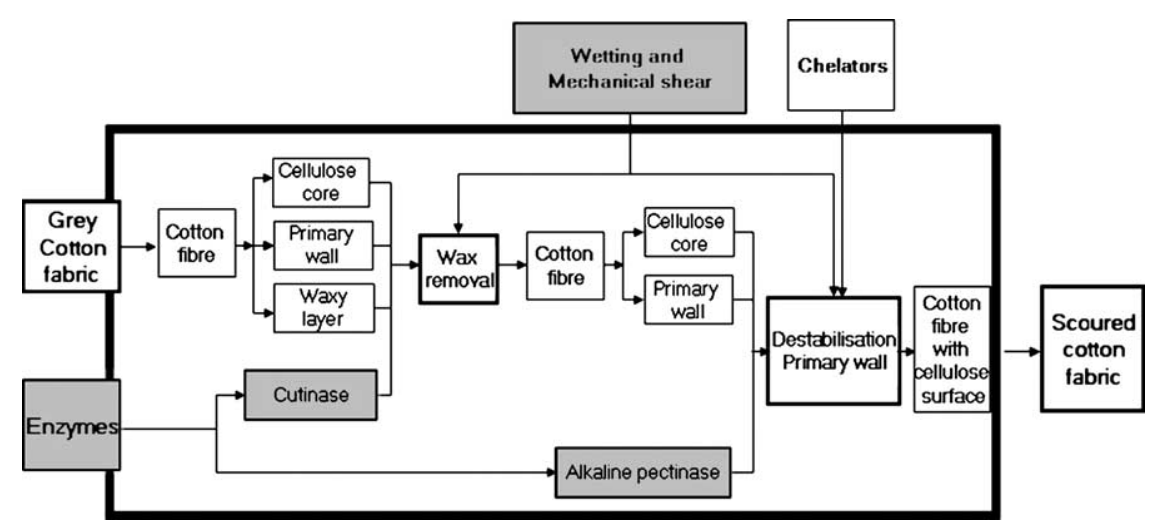

Figure 1. An illustration of various steps identified to achieve a rapid and efficient enzymatic cotton scouring process. 


\section{Fabric}

The fabric used was an industrially de-sized $280 \mathrm{~g}$ $\mathrm{m}^{-2}$ plain-woven $100 \%$ cotton fabric. The uniformity of the fabric in terms of pore volume distribution (PVD) was confirmed with an auto-porosimeter to eliminate the effect of irregular or interconnected pores. Prior to scouring, fabrics were sometimes treated with n-hexane $\left(30 \mathrm{~min}, 75^{\circ} \mathrm{C}\right)$, to study the effect of wax removal on enzyme performance and/or as a benchmark. $\mathrm{NaOH}$ scoured cloth was prepared in batch mode, resembling industrial process conditions $(0.25 \mathrm{M} \mathrm{NaOH}$ in the presence of commercial scouring additives at $95^{\circ} \mathrm{C}$ for $180 \mathrm{~min}$ ).

\section{Enzyme incubations}

Experiments where performed in a $1 \mathrm{~L}$ beaker in which three fabric samples of $5 \times 12 \mathrm{~cm}$ were treated in an enzyme solution in $500 \mathrm{~mL} 50 \mathrm{mM}$ Tris- $\mathrm{HCl}$ buffer ( $\mathrm{pH} 8$ ). The beaker was placed in a temperature controlled water bath at $30^{\circ}$ or $50^{\circ} \mathrm{C}$. After the treatment, the fabric samples were rinsed in $500 \mathrm{~mL}$ of water at $90^{\circ} \mathrm{C}$ for $15 \mathrm{~min}$, to inactivate the enzymes. Thereafter, the samples were rinsed twice for $5 \mathrm{~min}$ in water at room temperature. Finally, the samples were kept on a flat acrylic surface to be dried in air for at least $24 \mathrm{~h}$ before evaluating the fabric samples. All the experiments were performed in duplicate if reproducible. Modifications of this protocol are explained in the text.

\section{Surface tension}

A bubble tensiometer (Sita online T60, Sita, Germany) was used to measure the equilibrium and dynamic surface tension of various surfactant solutions used in this study. By changing the gas flow rate, it was possible to alter the bubble formation time and consequently the adsorption time of the surfactants (from 0.03-60 s). At a bubble life-time of $55 \mathrm{~s}$, the generation of new surface is so slow that the surface tension approaches the equilibrium value.

\section{Structural contact angle}

The hydrophilicity of the fabric samples was measured in terms of structural contact angle with a TRI auto-porosimeter (Miller \& Tyomkin 1994; Agrawal et al. 2007). An auto-porosimeter gives additional information on the inter- and intra-yarn pore size distribution of the fabric sample. The advantage of an auto-porosimeter above other wetability experiments is that the results obtained are independent of the fabric density, and of the structure of the fabric, e.g. knitted or woven.

\section{Pectin removal}

Residual pectin on the fabric was analysed by staining with ruthenium red. The procedure is essential as suggested by Lange et al. (1998) and described in Novozymes standard operating procedure (Novozymes 2003).

\section{SEM}

SEM is a widely used technique to study surface topography. Various fabric samples were subjected to SEM analysis, to visualize changes of the surfaces. The magnification was varied from $\times 1000$ up to $\times 30,000$.

\section{Results and discussion}

\section{Wax removal with cutinase}

To explore the potential of the fungal cutinase from F. solani pisi for degradation of cotton waxes, three different experiments were done with the standard fabric as a substrate: (A) cutinase, (B) $n$-hexane extracted fabric, the benchmark because nearly all surface waxes will be removed, and (C) a blank for sample A. The results of the treatments are presented in terms of the structural contact angle $\theta$ and pectin removal (Figure 2). From these results it is clear that cutinase is able to hydrolyse cuticle waxes. A structural contact angle of $70^{\circ}$ was obtained, which is quite close to the desired benchmark of $\sim 68^{\circ}$ (sample B). The average standard deviation in the structural contact angle measurements was in the range of $3-7^{\circ}$. The results show that the blank treatment had no effect on wax removal. Because all the treatments were targeted towards wax removal, pectin removal was negligible (less than $7 \%$ for all three samples), as expected.

To visualize the effect of the treatments, SEM pictures were taken (Figure 3). The treatments with cutinase (Figure 3A), and $n$-hexane (Figure 3B) remove surface waxes and unveil the primary wall of the cotton fibre. In these pictures, the rough and open primary wall surface is visible; the smooth waxy layer is absent. A complicated network in which non-cellulose materials are arranged in a criss-cross pattern can be seen. The surface of the cotton fibre of the blank treatment shows the smooth waxy layer with grooves, caused by the sub-surface complicated primary wall (Figure 3C).

Cutinase appears to be capable of achieving nearly the same structural contact angle results as the benchmark. Thereby, we have confirmed the potential of cutinase for the low-temperature cotton wax removal. Even under non-optimized conditions, our treatment time to remove waxes was only 


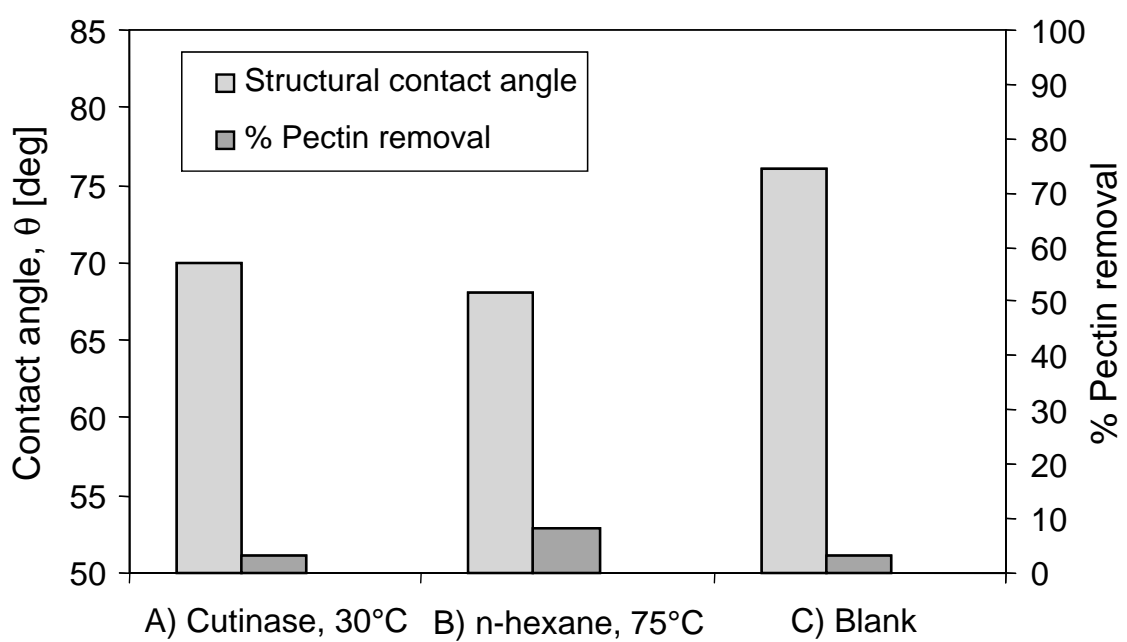

Figure 2. Comparison of cutinase treatment with $n$-hexane treated fabric. (A) cutinase incubation, $100 \mathrm{U} \mathrm{g}^{-1}$ of fabric at $30^{\circ} \mathrm{C}$ for $30 \mathrm{~min}$ (pH 8 in $50 \mathrm{mM}$, Tris- $\mathrm{HCl}$ buffer), (B) $n$-hexane extracted fabric and (C) blank for sample A.

$30 \mathrm{~min}$, which is much shorter than the $10-20 \mathrm{~h}$ reported by Degani et al (2002). This is most probably because our cutinase is from a different source (Fusarium solani pisi vs. Pseudomonas mandocino). Therefore, the complex structure of the two
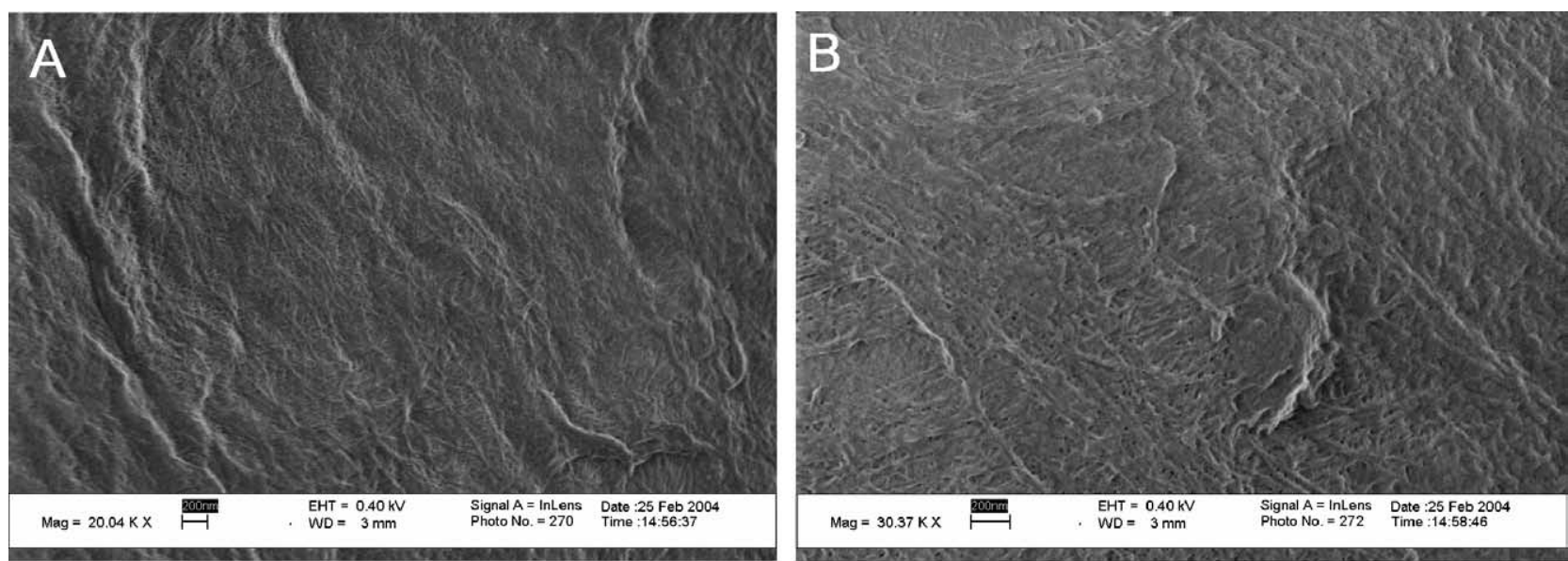

enzymes will be different. Low-temperature fast wax removal with cutinase from $F$ solani pisi clearly has the potential to be applied in an industrial cotton scouring process. We evaluated the potential of cutinase using a rational approach instead of a black

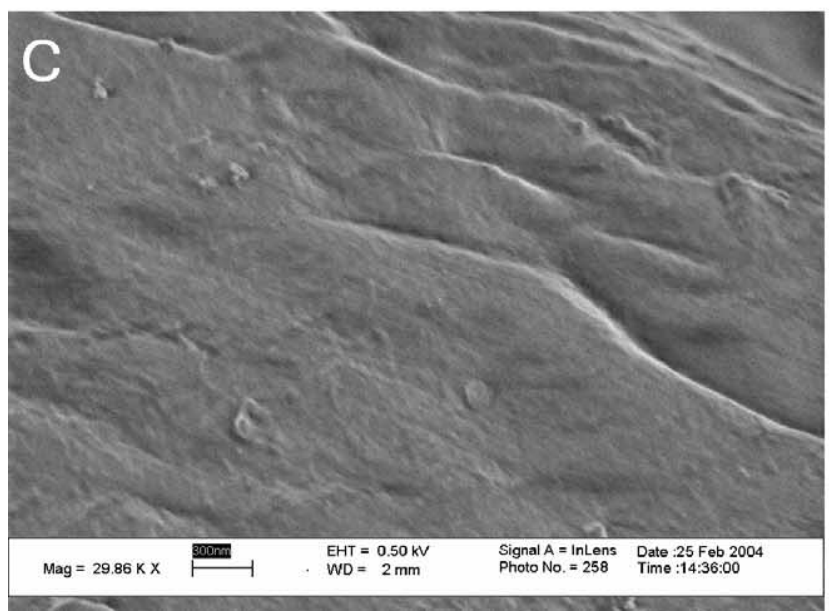

Figure 3. SEM pictures of the surface of the treated cotton fabric. A) cutinase incubation, $100 \mathrm{U} \mathrm{g}^{-1}$ of fabric at $30^{\circ} \mathrm{C}$ for $30 \mathrm{~min}$ (pH 8 in $50 \mathrm{mM}$, Tris- $\mathrm{HCl}$ buffer), (B) $n$-hexane extracted fabric and (C) blank for sample A. 
box (Figure 1). It was decided to explore the cutinase treatment together with surfactants and pectinase for an efficient cotton scouring process.

\section{Surfactants}

Surfactants facilitate the penetration of pectinase into the yarns, thereby improving the hydrolysis of pectin. It has been established that wax removal exposes the pectin surface to pectinase resulting in more efficient pectin hydrolysis (Agrawal et al. 2007). In order to apply cutinase and pectinase together, compatibility of cutinase with surfactants is essential. It is known that anionic surfactants negatively affect the catalytic action of cutinase (Egmond \& van Bemmel 1997; Pocalyko \& Tallman 1998; Creveld et al. 2001). Non-ionic surfactants are well known to be compatible with enzymes and only a small concentration is required to achieve a low surface tension (Egmond \& van Bemmel 1997; Pocalyko et al. 1998). As presented in Table I, a homologous series of 4 non-ionic surfactants, differing in the numbers of oxy-ethylene (EO) groups (6, 8,10 and 12), was selected to evaluate the effect of surfactants on cutinase performance. The structural contact angle was $\sim 0^{\circ}$ for EO 6,8 and 10 , while for EO 12 it was $\sim 17^{\circ}$. Hence, the wetting properties of EO 6, 8 and 10 are better than that of EO 12. To evaluate the effect of surfactants on cutinase kinetics, experiments were done in a $\mathrm{pH}$-stat with tributyrin as a substrate instead of fabric. The hydrolysis rate of tributyrin drops were evaluated in the presence of the different surfactants. The surfactant concentration was $1 \mathrm{~g} \mathrm{~L}^{-1}$, which is well above the CMC. The results are expressed in terms of hydrolytic rate of tributyrin (Table II). The hydrolytic rate of tributyrin was calculated from the slope of the initial rate of reaction between cutinase and tributyrin for the first $15 \mathrm{~min}$. As presented in Table II, the highest hydrolytic rate was found for cutinase with EO 8 (D) and with EO 10 (E). The increase in the rate of tributyrin hydrolysis is caused by the fact that the tributyrin drop size reduced in the presence of surfactants, thereby creating a higher surface available for cutinase. On the basis of these experiments and considering its properties from Table I, EO 10 (Triton X-100) was selected for further study.
Table II. Effect of different non-ionic surfactants on cutinase performance with tributyrin as substrate. Experiments in a $\mathrm{pH}-$ stat, with $1 \mathrm{mM}$ Tris- $\mathrm{HCl}$ buffer at $\mathrm{pH} 8,30^{\circ} \mathrm{C}, 50 \mathrm{U}$ cutinase and $0.5 \mathrm{~mL}$ tributyrin.

\begin{tabular}{llc}
\hline SN & \multicolumn{1}{c}{ Reaction } & $\begin{array}{c}\text { Hydrolytic rate of tributyrin } \\
\left(\mu \mathrm{mol} \mathrm{min} \mathrm{min}^{-1}\right)\end{array}$ \\
\hline A & Blank & 0.42 \\
B & Cutinase only & 6.23 \\
C & Cutinase +EO 6 & 10.61 \\
D & Cutinase +EO 8 & 15.15 \\
E & Cutinase +EO 10 & 15.16 \\
F & Cutinase +EO 12 & 13.62 \\
\hline
\end{tabular}

Petersen et al. (1998) reported that the increased hydrophilicity of the substrate surface negatively affects cutinase action. So we have to deal with two counteracting mechanisms: increased cutinase activity due to an increase in the surface area and a decreased cutinase activity caused by the increased hydrophilicity of the surface. To confirm this, three experiments were done in a $\mathrm{pH}$-stat at constant cutinase concentration for increasing Triton X-100 concentration and different amounts of tributyrin. The results are shown in Figure 4. The hydrolytic rate of cutinase (without surfactant) at $15 \mathrm{~min}$ has been taken as the point of reference and considered as $100 \%$ activity. All curves in Figure 4 show an initial decrease in hydrolysis rate corresponding to the initial increase in Triton X-100, up to the CMC (i.e. $\sim 0.13 \mathrm{~g} \mathrm{~L}^{-1}$ ); thereafter, the hydrolytic rate was proportional to the increase in Triton X-100. The increase in hydrophilicity had a negative effect on cutinase activity; this negative effect was counteracted by an increase in tributyrin concentration $(1 \mathrm{~mL})$. In this system, cutinase kinetics are substrate limited.

In the experiments described above a model substrate, tributyrin, was used instead of cotton fabric. To evaluate the effect of surfactants on cutinase performance on cotton fabrics the rate of wax hydrolysis on cotton fabrics was measured in a $\mathrm{pH}$-stat as a function of the Triton X-100 concentration. The structural contact angle was determined after treatment of the fabric. The results are shown in Figure 5. Initially, the rate decreased to $40 \%$ of the original value. This was due to the increased hydrophilicity of the fabric surface. $70 \%$ of original activity

Table I. Some properties of the different surfactants used (Kissa 1987; Rosen 1978).

\begin{tabular}{|c|c|c|c|c|c|}
\hline Surfactant & $\begin{array}{l}\text { No. EO } \\
\text { groups }\end{array}$ & HLB number & $\begin{array}{l}\text { Cloud point } \\
\left({ }^{\circ} \mathrm{C}\right)\end{array}$ & Mol. wt. & $\begin{array}{l}\text { Equilibrium surface } \\
\text { tension }\left(\mathrm{mN} \mathrm{m}^{-1}\right)\end{array}$ \\
\hline Polyoxyethylene 6 myristyl ether & 6 & 11.7 & $<30$ & 478.7 & 27.0 \\
\hline Polyoxyethylene 8 lauryl ether & 8 & 12.3 & $35-38$ & 538.7 & 27.7 \\
\hline Triton X-100 or Octylphenol ethoxylate & $9-10$ & 13.8 & 65 & 625 & 28.1 \\
\hline Tergitol15-S-12 or Secondary alcohol ethoxylate & 12 & 14.5 & 89 & 728 & 31.2 \\
\hline
\end{tabular}




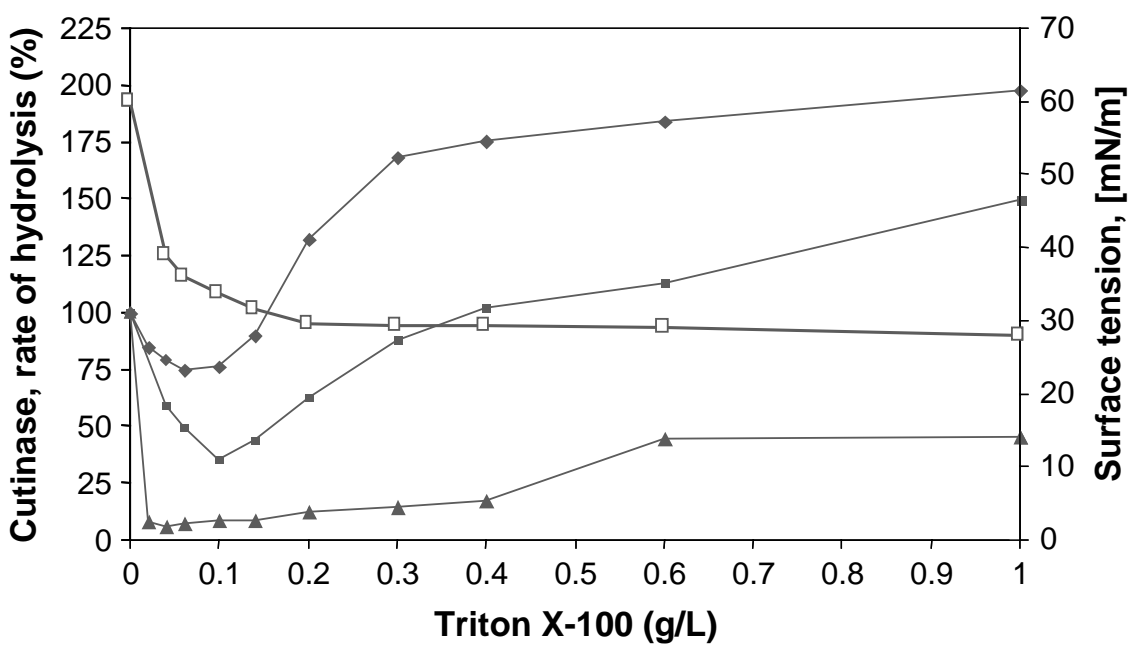

Figure 4. Hydrolysis rate and equilibrium surface tension as a function of increasing Triton X-100 concentration for different tributyrin concentrations (pH-stat experiment, $50 \mathrm{U}$ of free cutinase), $\mathbf{\Delta}=0.1 \mathrm{~mL}$ tribytirin, $\mathbf{\square}=0.5 \mathrm{~mL}$ tributyrin, $\diamond=1.0 \mathrm{~mL}$ tributyrin and $\square=$ equilibrium surface tension.

was retained at the higher surfactant concentrations ( $c_{\text {Triton } \mathrm{X}-100}>0.3 \mathrm{~g} \mathrm{~L}^{-1}$ ). It is known that the intrayarn pores affect mass transfer and wetting rates (Rosen 1978; Kissa 1987; Nierstrasz \& Warmoeskerken 2003). Improved wetting makes a larger surface area available, partially counteracting the negative effect of increased hydrophilicity. The explanation of the results is similar to that given above.

When the structural contact angle of cutinase treated fabrics in the presence or absence of Triton $\mathrm{X}-100$ is compared with $\mathrm{n}$-hexane treated fabrics, the benchmark (Figure 6), both of the treatments are comparable with $n$-hexane treatment. Interestingly, $n$-hexane extraction followed by a cutinase treatment yielded a contact angle of $\sim 66^{\circ}$, compared with $\sim 68^{\circ}$ for $n$-hexane only. In the experiment where the $n$-hexane treatment was followed by a cutinase treatment, we have removed all waxes. The result of the treatment with cutinase and Triton X-100 is comparable with this. The results clearly demonstrate that rapid low-temperature wax removal is possible with cutinase especially in combination with Triton X-100. Because of the dramatically reduced time to remove cotton waxes, cutinase now has the potential to be used in lowtemperature industrial cotton scouring process in combination with pectinases.

\section{Evaluation of incubation conditions}

The sensitivity and optima of parameters such as $\mathrm{pH}$, temperature, ionic strength, enzyme concentration

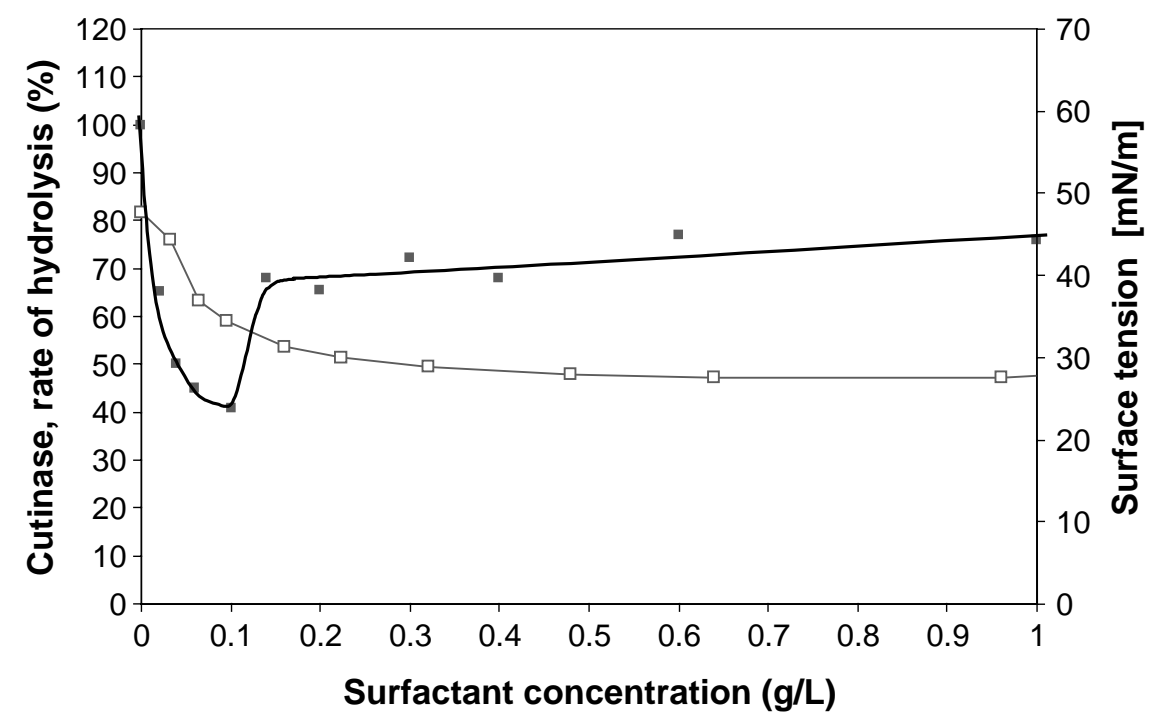

Figure 5. Rate of hydrolysis and equilibrium surface tension as a function of Triton X-100 concentration measured in a $\mathrm{pH}$-stat, $\mathbf{\square}=$ rate of hydrolysis and $\square=$ equilibrium surface tension (50 U cutinase, $0.5 \mathrm{~g}$ cotton fabric). 


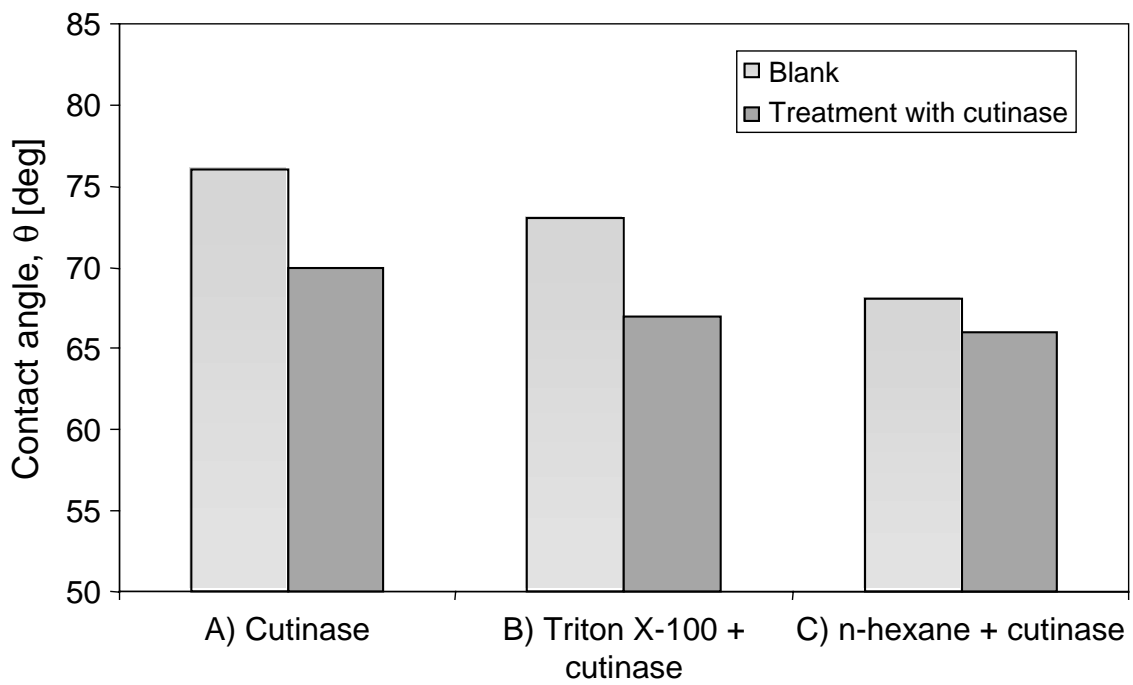

Figure 6. Structural contact angle of cotton fabric as a function of different treatments: A) cutinase $\left(100 \mathrm{U} \mathrm{g} \mathrm{g}^{-1}, 30^{\circ} \mathrm{C}\right.$ for $30 \mathrm{~min}, \mathrm{pH} 8$, $50 \mathrm{mM}$ Tris-HCl buffer), B) $1 \mathrm{~g} \mathrm{~L}^{-1}$ Triton X-100 and cutinase ( $100 \mathrm{U} \mathrm{g}^{-1}$ of fabric $30^{\circ} \mathrm{C}$ for $30 \mathrm{~min}, \mathrm{pH} 8,50 \mathrm{mM} \mathrm{Tris-} \mathrm{HCl}$ buffer $\left.), \mathrm{C}\right)$ $n$-hexane extraction at $75^{\circ} \mathrm{C}$ for $30 \mathrm{~min}$.

and incubation time for cotton fabric were determined. The effect of $\mathrm{pH}$ and temperature was determined on cotton fabrics, as well as on tributyrin in the $\mathrm{pH}$-stat. The optimum parameters are listed in Table III. The evaluated optima for $\mathrm{pH}$ and temperature coincide with the results from Degani et al. (2002). Egmond \& van Bemmell (1997) reported that at alkaline $\mathrm{pH}$, activity and adsorption of cutinase is favourable towards its substrates. The temperature optimum found in $\mathrm{pH}$-stat experiments coincides with the temperature optimum found with the fabric. Creveld et al. (2001) demonstrated irreversible inactivation of cutinase above $40^{\circ} \mathrm{C}$. The optimum buffer concentration corresponds to a structural contact angle of $\sim 70^{\circ}$ (Table III). Increasing buffer strength above $50 \mathrm{mM}$ did not result in an additional improvement in structural contact angle. Cutinase releases free fatty acids from triglycerides in the bulk liquid. Since the liberated fatty acids are negatively charged (above $\mathrm{pK}$ value), this may reduce the $\mathrm{pH}$ in the system, hence a stronger buffer is desired.

The effect of cutinase concentration on cotton wax removal has been explored by increasing the concen-

Table III. Optimum incubation conditions determined for cutinase for F. solani pisi on cotton fabrics as a substrate.

\begin{tabular}{lll}
\hline SN & \multicolumn{1}{c}{ Parameter } & \multicolumn{1}{c}{ Optima } \\
\hline 1 & PH & $\mathrm{pH} 8-9$ \\
2 & Temperature & $25-30^{\circ} \mathrm{C}$ \\
3 & Ionic strength of the buffer & $50 \mathrm{mM}$ Tris- $\mathrm{HCl}$ buffer, \\
& medium & $\mathrm{pH} 8.0$ \\
4 & Enzyme concentration & $100 \mathrm{U}$ cutinase $\mathrm{g}^{-1}$ cotton \\
& & fabric \\
5 & Time & $15-30 \mathrm{~min}$ \\
\hline
\end{tabular}

tration from $10 \mathrm{U} \mathrm{g}^{-1}$ to $300 \mathrm{U} \mathrm{g}^{-1}$ of cotton fabric. A structural contact angle of $70^{\circ}$ was achieved at a cutinase concentration of $100 \mathrm{U} \mathrm{g}^{-1}$. An increase up to $300 \mathrm{U} \mathrm{g}^{-1}$ did not improve the structural contact angle. The benchmark (treatment with n-hexane) has a structural contact angle of $\sim 68^{\circ}$, which means that $100 \mathrm{U} \mathrm{g}^{-1}$ cutinase is capable of removing a high percentage of the surface waxes.

Determination of the incubation time needed to remove waxes from cotton fibre is essential for possible industrial application of cutinase in the scouring process. The incubation time was varied from 1 to $120 \mathrm{~min}$ (Figure 7). The optimal conditions derived in earlier experiments were used $\left(30^{\circ} \mathrm{C}, 50 \mathrm{mM}\right.$ Tris- $\mathrm{HCl}$ buffer $\mathrm{pH} 8$ and $100 \mathrm{U}$ $\mathrm{g}^{-1}$ of cutinase). The results show that the structural contact angle changes rapidly from $\sim 77^{\circ}$ to $\sim 71^{\circ}$ in the first $15 \mathrm{~min}$ and reaches $\sim 70^{\circ}$ after just $30 \mathrm{~min}$. A longer incubation time did not lead to an improved structural contact angle. Thus, cutinase appears to be capable of achieving nearly the same structural contact angle results as the benchmark under optimized conditions, with a treatment time reduced to just $15-30 \mathrm{~min}$. Degani et al. (2002) reported that cutinase alone can achieve a wetting time of 20-30 s after incubating for almost $20 \mathrm{~h}$. The wetting time was measured using a drop test. It was reported that a wetting time of 20-30 s was the best result that can be achieved by the commonly used lipolytic enzymes, such as lipases and, hence, considered to be the benchmark value (Degani et al. 2002). In this study, we consider $n$-hexane extracted fabric as a benchmark, assuming that almost all the waxes from the cotton surface are removed. However, as mentioned earlier, it is 


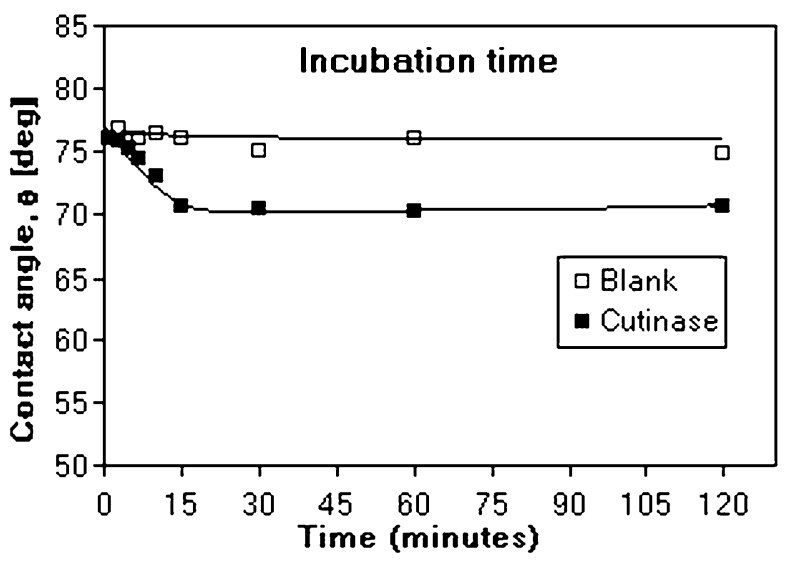

Figure 7. Effect of incubation time for optimal cutinase performance. Experiments were conducted with $100 \mathrm{U} \mathrm{g}^{-1}$ cutinase using $50 \mathrm{mM}$ Tris- $\mathrm{HCl}$ buffer at $\mathrm{pH}$ 8. $\square=$ blank without cutinase and $\mathbf{\square}=$ cutinase treatment.

complicated to compare our results with those of Degani et al. (2002) due to the many other experimental variables.

\section{Cutinase and pectinase}

To explore whether an increased hydrophilicity due to wax removal with cutinase also leads to improved pectinase performance, the removal of pectin from the cotton fibre was determined as a function of time. Four different experiments were done: (A) only pectinase, (B) $n$-hexane extracted fabric followed by pectinase treatment, $(\mathrm{C})$ cutinase followed by pectinase treatment, and (D) cutinase and Triton $\mathrm{X}-100$ treatment followed by pectinase treatment. The results are presented in Figure 8. In earlier work, we showed that the rate of pectin removal increases nearly 1.65 times if waxes are removed with n-hexane prior to the pectinase treatment (Agrawal et al. 2007). For treatments C and D, $56-58 \%$ of the pectin was removed in the first $5 \mathrm{~min}$, which is slightly less than with $n$-hexane extraction (treatment B). After treatment with cutinase alone and in combination with Triton X-100, the rate of pectin removal was increased nearly 1.65 times. This is comparable with the benchmark. The total amount of pectin removed for treatment $\mathrm{C}$ and $\mathrm{D}$ was the same as for $n$-hexane extracted fabrics. It can be concluded that cutinase removes waxes efficiently, thereby exposing non-cellulose interconnections to the pectinase. The structural contact angle measurements and SEM pictures support these results.

It was also shown that cutinase and pectinase can be applied effectively together in one reactor vessel. Because the optimum temperature for cutinase is lower that for pectinase, the optimum temperature for cutinase was used. To compensate for the lower temperature the dosage of pectinase was increased from 13 to $52 \mathrm{U} \mathrm{g}^{-1}$ of fabric. It is important to realize that enzymes are relatively large molecules and mass transfer is known to be slower in enzymatic wet textile processes ( $\mathrm{Lu}$ 2005). Therefore, mechanical energy using a wedge apparatus was used to improve mass transfer. The role of mass transport in enzymatic scouring process is discussed in detail elsewhere (Agrawal et al. 2008). To complete the picture as illustrated in the last part of strategy (Figure 1), the best results are presented in Figure 9 and are compared with conventionally scoured fabric. The results are very encouraging. One-step scouring with cutinase, pectinase, Triton $\mathrm{X}-100$ and mechanical energy is achievable at $30^{\circ} \mathrm{C}$ in just 15 min. The benchmark, a structural contact angle of less than $53^{\circ}$, is achieved with cutinase and pectinase. This is comparable with conventionally scoured cotton fabrics.

\section{Conclusions}

A feasible strategy was developed to achieve a rapid benign bio-scouring process for cotton textiles. Application of cutinase for efficient low-temperature and rapid wax removal of cotton fibres is an important step towards achieving low-temperature scouring. We have shown that a fungal cutinase from F. solani pisi degrades and removes cotton waxes at a low-temperature $\left(30^{\circ} \mathrm{C}\right)$. Cutinase can achieve almost the same degree of wax removal as solvent extraction within $15 \mathrm{~min}$, which is far better than $10-20 \mathrm{~h}$ as reported by Degani et al. (2002). The results were obtained by measurement of the structural contact angle, pectin removal and SEM.

Surfactants play an important role in the efficiency of the scouring process. The compatibility of cutinase with surfactants was explored. Experiments were done in $\mathrm{pH}$-stat to demonstrate that the increased surface area for cutinase action counteracts the negative effect of increased hydrophilicity caused by 


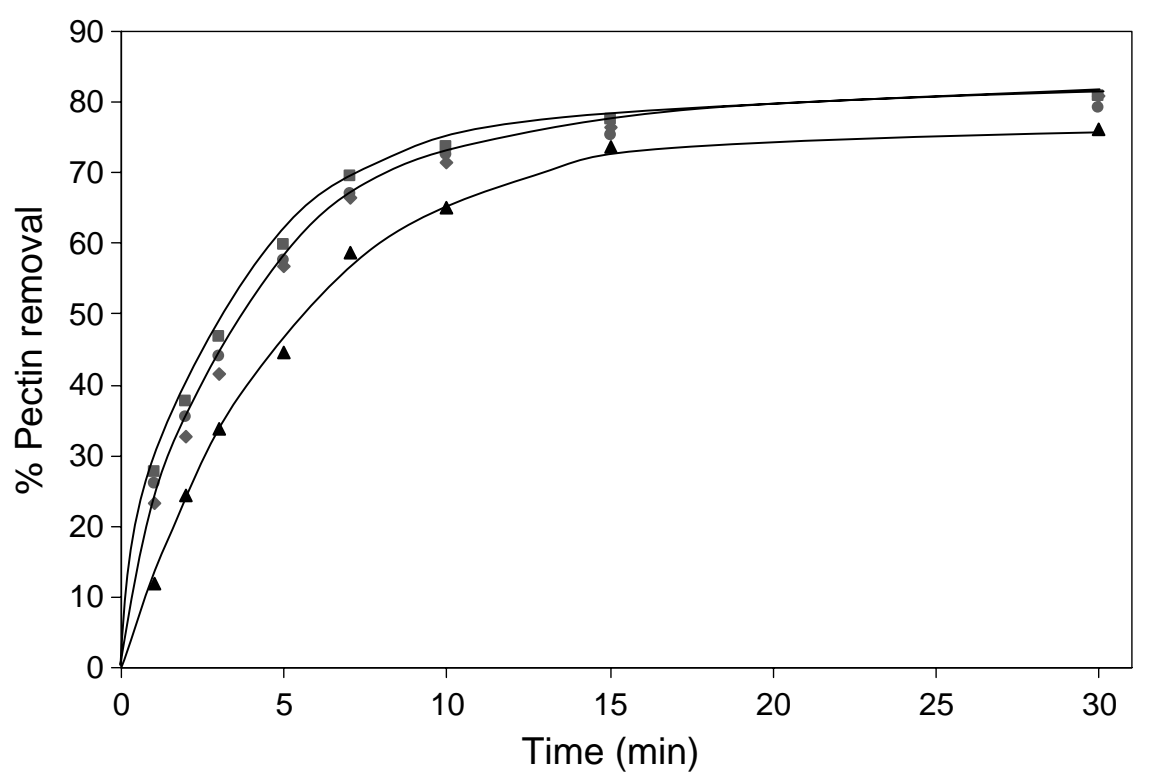

Figure 8. Pectin removal after pretreatment with cutinase or n-hexane. Pectinase $13 \mathrm{U} \mathrm{g}^{-1}$ of fabric, $50^{\circ} \mathrm{C}, 50 \mathrm{mM} \mathrm{Tris-} \mathrm{HCl}$ buffer $\mathrm{pH} 8$. Cutinase $100 \mathrm{U} \mathrm{g}^{-1}$ of fabric, $30^{\circ} \mathrm{C}, 50 \mathrm{mM}$ Tris-HCl buffer $\mathrm{pH} 8,1 \mathrm{~g} \mathrm{~L}^{-1}$ Triton X-100. $\boldsymbol{\Delta}$ =pectinase treatment only, $\mathbf{\square}=n$-hexane treatment prior to pectinase treatment, $\mathbf{Q}=$ cutinase treatment prior to pectianse treatment, $\diamond=$ cutinase + Triton $\mathrm{X}-100$ treatment prior to pectinase treatment.

surfactant. Cutinase is capable of removing cotton waxes even in the presence of high concentrations of Triton X-100.

An increase in the hydrolytic rate of pectinase was achieved after treatment with cutinase (with and without Triton X-100). The results clearly demonstrate that cutinase was able to increase the rate of pectin removal, equivalent to an $n$-hexane treatment prior to the pectinase treatment. Various parameters were evaluated such as $\mathrm{pH}$, temperature, ionic strength, enzyme concentration and incubation time. Cutinase is an effective tool in degrading and removing cotton wax at low-temperature without organic solvents. Cutinase from $F$ solani pisi has the potential in combination with pectinase to achieve a viable efficient low-temperature industrial cotton scouring process.

\section{Acknowledgements}

This work was supported by a grant of the European Commission (European Commission GROWTH

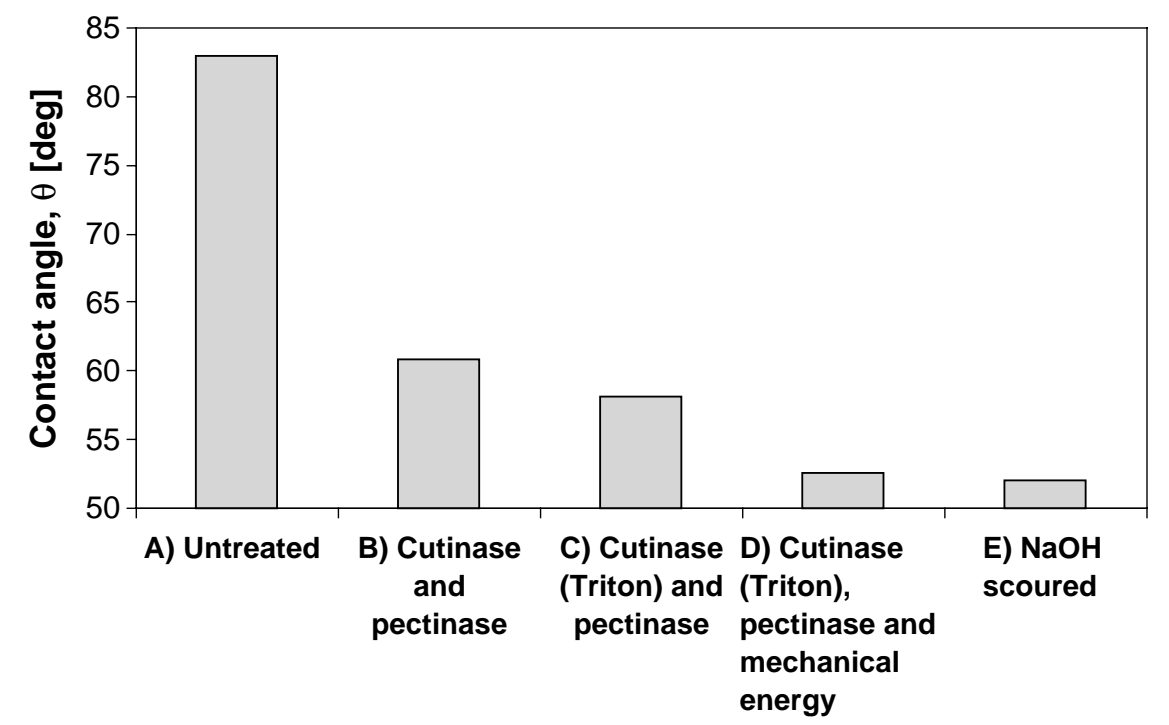

Figure 9. Structural contact angle for combined application on cotton fabrics. Cutinase $100 \mathrm{U} \mathrm{g}^{-1}$ and pectinase $52 \mathrm{U} \mathrm{g}^{-1}$ of fabric, Triton $\mathrm{X}-1001 \mathrm{~g} \mathrm{~L}^{-1}, 30^{\circ} \mathrm{C}, 15 \mathrm{~min}, 50 \mathrm{mM}$ Tris- $\mathrm{HCl}$ buffer $\mathrm{pH} 8$. Mechanical energy was provided by a mechanical wedge $\sim 9710 \mathrm{~N}$ $\mathrm{m}^{-2}$ for 100 strokes. 
Program; grant GRD-1999-10671, Continuous biopretreatment of cellulose fibres, BPT) and Royal Ten Cate. We would like to thank the foundation TGM and the Dutch Ministry of Economic Affairs for their financial support.

Declaration of interest: The authors report no conflicts of interest. The authors alone are responsible for the content and writing of the paper.

\section{References}

Agrawal PB, Nierstrasz VA, Klug-Santner BG, Guebitz GM, Lenting HBM, Warmoeskerken MMCG. 2007. Wax removal for accelerated cotton scouring with alkaline pectinase. Biotechnol J 2:306-315.

Agrawal PB, Nierstrasz VA, Warmoeskerken MMCG. 2008. Role of mechanical action in low temperature cotton scouring with $F$. solani pisi cutinase and pectate lyase. Enz Microb Technol 42:473-482.

Buchert J, Pere J. 2000. Scouring of cotton with pectinases, proteases and lipases. Text Chem Color AM D 31(5):48-52.

Creveld LD, Meijberg W, Berendsen HJC, Pepermans HAM. 2001. DSC studies of Fusarium solani pisi cutinase: consequences for stability in the presence of surfactants. Biophys Chem 92:65-75.

Degani O, Gepstein S, Dosoretz CG. 2002. Potential use of cutinase in enzymatic scouring of cotton fiber cuticle. Appl Biochem Biotech Part A Enz Eng Biotechnol 102-103:277289.

Egmond MR, de Vlieg J. 2000. Fusarium solani pisi cutinase. Biochimie 82:1015-1021.

Egmond MR, van Bemmel CJ. 1997. Impact of structural information on understanding lipolytic function. Methods Enzymol 284:119-129.

Etters JN, Husain PA, Lange NK. 1999. Alkaline pectinase: an eco friendly approach to cotton preparation. Text Asia 5:83-86.

Hartzell-Lawson MM, Hsieh Y-L. 1998. Enzymatic scouring to improve cotton fabric wettability. Text Res J 68(4):233-241.

Kissa E. 1987. Detergency: theory and technology. In: Gale Cutler W. (Ed) Surfactant Science Series. Vol 20, New York: Marcel Dekker Inc.

Klug-Santner BG, Schnitzhofer W, Vršanská M, Weber J, Agrawal PB, Nierstrasz VA, Guebitz GM. 2006. Purification and characterization of a new bioscouring pectate lyase from Bacillus pumilus BK2. J Biotechnol 121:390-401.

Kolattukudy PE. 2001. Polyesters in higher plants. Adv Biochem Eng Biotechnol 71:1-49.

This paper was first published online on iFirst on 11 August 2008.
Lange NK, Liu J, Husain Ph, Condon B. 1998. Book of papers on the International Conference and Exhibition of the AATCC, Philadelphia, USA, 463-471.

Lenting HBM, Zwier E, Nierstrasz VA. 2002. Identifying important parameters for a continuous bioscouring process. Text Res J 72:825-831.

Li Y, Hardin IR. 1997. Enzymatic scouring of cotton: effects on structure and properties. Text Chem Color 29(8):71-76.

Lin C-H, Hsieh Y-L. 2001. Direct scouring of greige cotton fabric with proteases. Text Res J 71:415-434.

Lu H. 2005. Insights into cotton enzymatic pretreatment. Internat Dyer 190(3):10-13.

Miller B, Tyomkin I. 1994. Liquid porosimetry: new methodology and applications. J Col Int Sci 62:163-170.

Miller GL. 1959. Use of dinitrosalcylic acid reagent for determination of reducing sugar. Anal Chem 31:1902-1904.

Moghe VV, Nabar PS. 2006. Bio-scouring: an ecological way of scouring. Colourage 53(2):95-96.

Nierstrasz VA, Warmoeskerken MMCG. 2003. Process Engineering and industrial enzyme applications. In: Cavaco-Paulo A, Gübitz GM, editors. Textile Processing with Enzymes. Cambridge: Woodhead Publishing Ltd.

Novozymes. 2003. Determination of pectin removal on cotton by ruthenium red dyeing. SOP No: EUS-SM-0103, 02/01 1-6.

Petersen SB, Jonson PH, Fojan P, Petersen EI, Neves-Petersen MT, Hansen RJ, Ishak S, Hough E. 1998. Protein engineering the surface of enzymes. J Biotechnol 66:11-26.

Pocalyko DJ, Tallman M. 1998. Effect of amphipaths on the activity and stability of Fusarium solani pisi cutinase. Enzyme Microb Technol 22:647-651.

Purdy RE, Kolattukudy PE. 1975. Hydrolysis of plant cuticle by plant pathogens: purification, amino acid composition, and molecular weight of two isozymes of cutinase and a nonspecific esterase from Fusarium solani pisi. Biochem 14:2824-2831.

Rosen MJ. 1978. Surfactants and Interfacial phenomena. 2nd edn. New York: John Wiley and Sons.

Sawada K, Toniko S, Ueda M, Wang XY. 1998. Bioscouring of cotton with pectinase enzyme. JSDC 114:333-336.

Svendsen A. 2000. Lipase protein engineering - review article. Biochim et Biophys Acta (BBA) - Protein Struct Molec Enzymol 1543:223-238.

Takagishi T, Yamamoto R, Kikuyam K, Arakawa H. 2001. Design and application of continuous bioscouring machine. AATCC Rev 1(8):32-35.

Tzanko T, Calafell M, Guebitz GM, Cavaco-Paulo. 2001. A biopreparation of cotton fabrics. Enzyme Microb Technol 29 (6-7):357-362.

Vertommen MAME, Nierstrasz VA, Veer MVD, Warmoeskerken MMCG. 2005. Enzymatic surface modification of poly(ethylene terephthalate). J Biotechnol 120:376-386. 